\title{
Correction to: Citation contagion: a citation analysis of selected predatory marketing journals
}

\author{
Salim Moussa ${ }^{1}$ (D) \\ Published online: 2 December 2020 \\ (c) Akadémiai Kiadó, Budapest, Hungary 2020
}

\section{Correction to: Scientometrics} https://doi.org/10.1007/s11192-020-03729-6

In the original publication of the article, the following reference was published incorrectly. This has been corrected with this Correction.

Teixeira da Silva, J. A. (2020). Cabell's International publishing blacklist: An interview with Kathleen Berryman. Journal of Radical Librarianship, 6, 16-23.

The original article has been corrected.

The original article can be found online at https://doi.org/10.1007/s11192-020-03729-6.

\section{Salim Moussa}

salimmoussa@yahoo.fr

1 Institut Supérieur des Études Appliquées en Humanités, Cité des Jeunes, 2133 Gafsa, Tunisie 